\title{
BELA, PANAFORIZADA E DO LAR: REFLEXÕES SOBRE UM CASO DE AFORIZAÇÃO
}

\author{
Rafael Prearo-Lima* \\ Instituto Federal São Paulo \\ Bragança Paulista, SP, Brasil
}

\author{
Patrícia Silvestre Leite Di lório** \\ Universidade Cruzeiro do Sul \\ São Paulo, SP, Brasil
}

\begin{abstract}
Resumo: Neste trabalho, analisamos o processo de aforização do título do perfil "Marcela Temer: bela, recatada e 'do lar',", publicado pela Revista Veja Online em 18 de abril de 2016. O período, marcado por polarizações políticas e sociais e pelo processo de impeachment da Presidente Dilma Rousseff, mostrou-se profícuo para a (con/di)vergência das memórias instituidas pela tríade "bela, recatada e do lar" e, em consequência, para a discussão do sexismo brasileiro que repercutiu, entre outros, em notícias, críticas e textos humorísticos. Buscamos verificar como o título do perfil é construído pelo processo de remissão, constituindo-se em uma aforização-eco, como ele é panaforizado e metaforizado. Para a análise, fazemos uso de conceitos de Análise do Discurso, principalmente os propostos por Maingueneau (2010, 2012 e 2014) e Baronas (2013).
\end{abstract}

Palavras-chave: Mídia. Enunciação Aforizante. Panaforização. Metaforização.

\section{CONSIDERAÇÕES INICIAIS}

Ao buscarmos a frase "Bela, recatada e do lar" no site de buscas Google, encontramos mais de 380.000 resultados. Notícias, reportagens, memes, textos de blogs, vídeos, imagens de famosos e anônimos são exemplos da viralização da frase que foi utilizada como parte do título para o perfil de Marcela Temer, "Marcela Temer: bela, recatada e 'do lar'”, apresentado na versão online da Revista Veja ${ }^{1}$ (disponível em anexo), em 18 de abril de 2016, pela jornalista Juliana Linhares ${ }^{2}$.

\footnotetext{
* Doutorando em Estudos Linguísticos na Universidade Estadual Paulista (Unesp), Instituto de Biociências, Letras e Ciências Exatas (Ibilce), campus São José do Rio Preto. Docente do IFSP, Bragança Paulista. Email: rprearo@hotmail.com

** Doutora em Língua Portuguesa pela Pontifícia Universidade Católica de São Paulo (PUC/SP), Docente do Mestrado em Linguística da Universidade Cruzeiro do Sul - SP. E-mail: patricia.leite@cruzeirodosul.edu.br

1 O site da Editora Abril informa que a Revista Veja possui um público tanto masculino (48\%) como feminino (52\%) pertencentes à classe $\mathrm{AB}(62 \%)$. A revista, que conta com mais de 8,6 milhões de leitores de sua versão impressa, 160 mil da versão digital e cerca de 12 milhões de visitantes no portal veja.com, além de 6 milhões de seguidores no Twitter e no Facebook, ficou conhecida por sua postura contra Luís Inácio Lula da Silva e pró-impeachment de Dilma Rousseff.

${ }^{2}$ Juliana Linhares é editora responsável por artigos nos campos de estilo de vida, beleza e entretenimento.
} 
A frase e o perfil poderiam ter passado despercebidos pelo grande público não fosse o clima político e a iminência do impeachment da Presidente Dilma Rousseff. É necessário ressaltar que, desde 2013, várias manifestações políticas e sociais separavam opiniões e, por consequência, a população brasileira. Essa polarização se refletiu para as mídias que exploravam slogans como "Concordando ou não, siga a Folha, porque ela tem suas posições, mas sempre publica opiniões diferentes". Da mesma forma, anônimos e famosos assumiam suas opiniões em páginas no Facebook e mensagens no Twitter. Era um momento de escolher "seu lado", de declarar-se a favor ou contra um tema ou o partido X. Assim, as revistas demonstravam sua linha editorial e seu viés político.

Foi nesse contexto político-social, quatro meses antes da votação que confirmou o impeachment e a saída do poder da presidente eleita, que o perfil de Marcela Temer, mulher do então vice-presidente Michel Temer, foi publicado como se fosse um anúncio da "quase primeira dama" do país. Muito mais do que o perfil, a escolha do título "Bela, recatada e do lar" se tornou mais uma possibilidade de polarização de opiniões.

Maingueneau (2013) propõe que todo gênero do discurso tem por objetivo modificar a circunstância da qual ele participa. Desta forma, traçar o perfil de Marcela Temer e colocá-la como "quase primeira dama", na linha fina que acompanha o título "A quase primeira-dama, 43 anos mais jovem que o marido, aparece pouco, gosta de vestidos na altura dos joelhos e sonha em ter mais um filho com o vice" -, é definir uma posição editorial para a revista, apoiando o processo de destituição do cargo de Dilma Rousseff. Mais do que isso, é antecipar o resultado do impeachment presidencial.

Por ter sido publicada em uma revista brasileira de circulação nacional com cadernos especiais para algumas localidades, a matéria veiculada em abril de 2016, na efervescência de um momento político singular, pode ser considerada provocadora, não apenas por explicitar sua posição a favor do impeachment, mas por promover a discordância de seu público feminino ao distanciar a figura de Marcela da grande maioria dos leitores, recuperando a memória de um modelo bíblico a ser seguido:

\footnotetext{
${ }^{10}$ Uma esposa exemplar; feliz quem a encontrar! É muito mais valiosa que os rubis.

${ }^{11}$ Seu marido tem plena confiança nela e nunca lhe falta coisa alguma.

${ }^{12}$ Ela só lhe faz o bem, e nunca o mal, todos os dias da sua vida.

${ }^{13}$ Escolhe a lã e o linho e com prazer trabalha com as mãos.

${ }^{14}$ Como os navios mercantes, ela traz de longe as suas provisões.

${ }^{15}$ Antes de clarear o dia ela se levanta, prepara comida para todos os de casa, e dá tarefas às suas servas.

${ }^{16}$ Ela avalia um campo e o compra; com o que ganha planta uma vinha.

${ }^{17}$ Entrega-se com vontade ao seu trabalho; seus braços são fortes e vigorosos.

${ }^{18}$ Administra bem o seu comércio lucrativo, e a sua lâmpada fica acesa durante a noite.

${ }^{19}$ Nas mãos segura o fuso e com os dedos pega a roca.

${ }^{20}$ Acolhe os necessitados e estende as mãos aos pobres.

${ }^{21}$ Não teme por seus familiares quando chega a neve, pois todos eles vestem agasalhos.

${ }^{22}$ Faz cobertas para a sua cama; veste-se de linho fino e de púrpura.

${ }^{23}$ Seu marido é respeitado na porta da cidade, onde toma assento entre as autoridades da sua terra. (Provérbios 31:10-23 - NVI)
} 
Outro aspecto restaurado pelo título é a construção tripartite, formada por dois adjetivos e uma locução adjetiva, que reconstrói a célebre frase do imperador romano Júlio César "Veni, vidi, vici" (Vim, vi, venci). Essa fórmula triádica, segundo Dias (1996), é modelo para a elaboração de manchetes no jornalismo popular, pois "revelam a intertextualidade, no que o fenômeno linguístico tem de mais simples e acessível na memória do povo" (p. 72). Embora não constituída pela mesma classe de elementos, podemos considerar que se trata de frases nominais - é bela, é recatada e é do lar - assim, mais do que qualificar a personagem retratada, essa forma tríplice de construção dá força de máxima para a frase e, assim como aconteceu com a frase do imperador, possibilita uma (pan)aforização.

A grande repercussão observada nas diferentes formas de recuperação desse título em contextos diversos nos motivam a examiná-lo linguística e discursivamente. Desta forma, nosso objetivo é verificar como o título do perfil de Marcela Temer passa pelo processo de aforização, depois panaforização e, até mesmo, metaforização, e que efeitos de sentido surgem a partir de novas enunciações. Para tanto, valer-nos-emos da Análise do Discurso, principalmente dos preceitos propostos por Maingueneau (2010, 2012, 2014), bem como reflexões de Baronas (2013) sobre o assunto.

Neste trabalho, apresentaremos primeiramente informações sobre o gênero discursivo, o suporte e a organização textual do perfil de Marcela Temer. Em seguida, teceremos algumas considerações sobre o modo pelo qual trechos destacáveis funcionam como enunciados aforizantes que são recuperados, se transformam e até irrompem em outras línguas.

\section{BELA, DESTACADA E DO MUNDO}

Para iniciarmos a análise, faremos breves considerações a respeito de alguns conceitos importantes. Maingueneau (2014) explica que determinados fragmentos são destacáveis de seu texto-fonte e, quando algum é enfatizado em relação a seu entorno textual, ocorre uma sobreasseveração. De forma geral, esse tipo de destacamento pode ser marcado de diferentes modos (por exemplo, por sua posição no texto, por um valor generalizante, pelo metadiscurso etc.).

Ao observar como determinadas sobreasseverações quando utilizadas, por exemplo, em títulos e manchetes de jornais, Maingueneau (2010) constata divergências entre os dois tipos de enunciados produzidos. Segundo ele, essas alterações apresentam uma mudança no estatuto pragmático do enunciado destacado, em que este deixa de ser apenas um fragmento do texto, tendo seu funcionamento sob um regime específico de enunciação: a aforização. O autor opõe, dessa forma, uma enunciação aforizante a uma enunciação textualizante, esclarecendo que a diferença entre um enunciado aforizante e um texto não está em sua dimensão, mas em sua ordem, como demonstrado graficamente pelo Quadro 1. 


\section{Quadro 1 - Esquema das ordens enunciativas de Maingueneau (2010)}

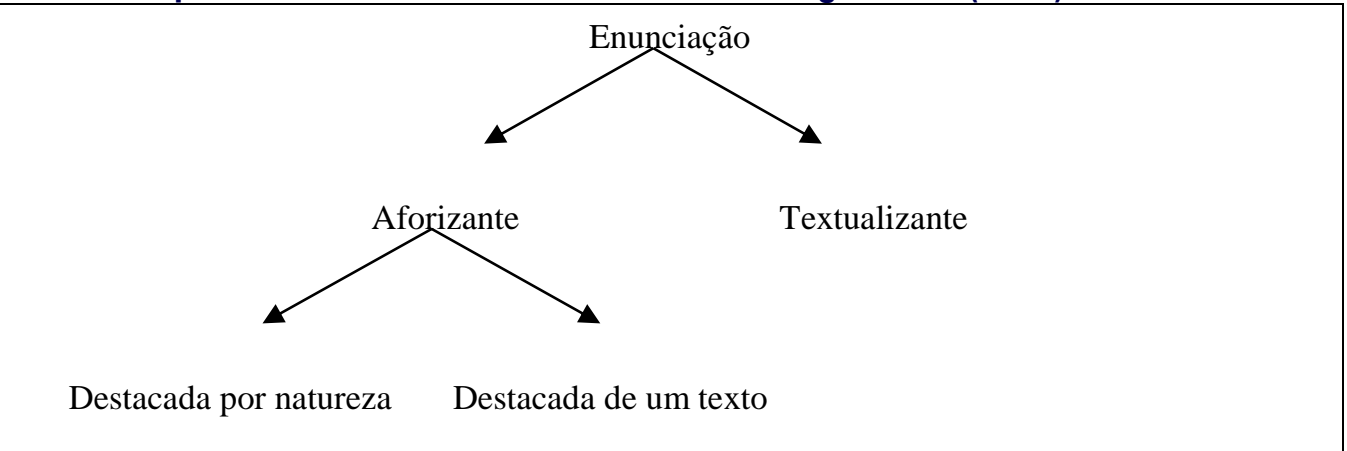

Fonte: Maingueneau, 2010, p. 13

No corpus selecionado para esta análise, notamos que o título "bela, recatada e 'do lar'" não é a aforização de um enunciado citado no texto, que Maingueneau (2014) denomina como aforização canônica. Há, nesse caso, um problema suscitado na definição de aforização, para a qual o autor apresenta a seguinte solução:

Com esses grupos nominais predicativos, tal ilusão constitutiva da aforização se dissipa [...]. Seria melhor falar aqui de aforização-eco, na qual a frase não verbal se apresenta como o traço de uma aforização prévia completa, que, na realidade, é construída por essa remissão. (MAINGUENEAU, 2014, p. 54, grifo do autor)

De fato, "bela, recatada e do lar" funciona como um tipo de remissão a diferentes ideias detalhadas no texto, resumindo seus conceitos principais. A noção de "bela", por exemplo, pode ser recuperada nos seguintes excertos:

(1) Marcela comporta em seu curriculum vitae [...] dois concursos de miss no interior de São Paulo (representando Campinas e Paulínia, esta sua cidade natal). Em ambos, ficou em segundo lugar.

(2) Por algum tempo, frequentou o salão de beleza do cabeleireiro Marco Antonio de Biaggi, famoso pela clientela estrelada.

(3) Na opinião do cabeleireiro, Marcela "tem tudo para se tornar a nossa Grace Kelly".

(4) "Marcela sempre chamou atenção pela beleza [...]”, diz sua irmã mais nova, Fernanda Tedeschi.

Em (1), a beleza de Marcela é atestada por sua participação em concursos de miss. Ainda que não tenham sido eventos de muita expressão, sua posição de destaque indica alguém com “currículo na área”, como sugerido. Já em (2) e (3), é possível resgatarmos a questão da beleza de Marcela por sua ida a um salão renomado e pela comparação que seu cabeleireiro estabelece com Grace Kelly, atriz norte-americana ícone de beleza e que, à semelhança de Marcela Temer, era casada com um homem de vida pública (Rainier III, príncipe de Mônaco). Por fim, Fernanda Tedeschi também confirma a beleza da própria irmã no excerto (4).

Consideremos os excertos a seguir, cujos efeitos de sentido remetem à noção de "recatada": 
(5) A quase primeira-dama [...] aparece pouco, gosta de vestidos na altura dos joelhos [...]

(6) [...] era "educadíssima", lembra o cabeleireiro.

(7) Em todos esses anos de atuação política do marido, ela apareceu em público pouquíssimas vezes.

(8) "Marcela sempre chamou atenção pela beleza, mas sempre foi recatada", diz sua irmã mais nova, Fernanda Tedeschi.

(9) "Ela gosta de vestidos até os joelhos e cores claras", conta a estilista Martha Medeiros.

Notamos que a ideia de pudor e modéstia associada ao termo recatada é evidenciada pelo modo de se vestir de Marcela - excertos (5) e (9). O uso de "vestidos até os joelhos e cores claras" (em oposição a "vestidos curtos e cores gritantes", por exemplo) restaura a memória discursiva do vestir-se com discrição e sobriedade, como "à moda antiga", sem se expor, em consonância com sua atitude "educadíssima" - excerto (6) - sugerindo alguém de classe, de elevada posição social. Agrega a essa construção a foto utilizada na veiculação da matéria de Veja, em que Marcela usa roupas discretas, sem decotes ou cores não consideradas sóbrias.

Outra característica de recato recai no fato de Marcela fazer poucas aparições públicas - excertos (5) e (7) - mesmo ao exercer seu papel de esposa de vice-presidente ${ }^{3}$, quando o que é esperado é que seja alguém que se exponha mais e não apareça em público somente "pouquíssimas vezes".

É interessante contrastarmos essas características com o que é posto no excerto (8), em que a irmã de Marcela confirma sua beleza e a contrapõe ao fato de ela ser "recatada". Ao fazer uso da conjunção adversativa mas, Fernanda Tedeschi supõe que o chamar "atenção pela beleza" não pode estar associado ao ser "recatado".

Quanto a "do lar", destacamos os excertos a seguir:

(10) [...] sonha em ter mais um filho com o vice.

(11) Marcela é uma vice-primeira-dama do lar. Seus dias consistem em levar e trazer Michelzinho da escola, cuidar da casa, em São Paulo, e um pouco dela mesma também (nas últimas três semanas, foi duas vezes à dermatologista tratar da pele).

(12) Bacharel em direito sem nunca ter exercido a profissão, Marcela comporta em seu curriculum vitae um curto período de trabalho como recepcionista [...].

(13) Está constantemente de olho nas redes sociais e mantém o marido informado sobre a temperatura ambiente.

(14) Um fica longe do outro a maior parte da semana, uma vez que Temer mora de segunda a quinta-feira no Palácio do Jaburu, em Brasília, e Marcela permanece em São Paulo, quase sempre na companhia da mãe.

Esses excertos são usados para validar a imagem de Marcela como alguém "do lar": alguém que tem na maternidade seu sonho (excerto 10) e que procura exercer bem seu papel de mãe na rotina com o filho (excerto 11). Apesar de sua formação acadêmica, Marcela abriu mão da carreira para dar suporte ao marido (excertos 12 e 13) e, mesmo estando distante dele parte do tempo, tem a companhia da mãe (excerto 14). Em conjunto, essa construção resgata a memória discursiva da dona de casa como conhecida há algumas décadas.

\footnotetext{
${ }^{3}$ Quando da publicação da matéria pela Revista Veja, em abril de 2016.
} 
Podemos, então, concluir que, em sua matéria, Veja constrói o ethos discursivo (MAINGUENEAU, 1997, 2008a, 2008b, 2010, 2013) de Marcela Temer como sendo de alguém "bela, recatada e do lar" e, ao utilizar tal caracterização no título, construído como remissão àquilo que é destaque no texto, produz uma aforização-eco (MAINGUENEAU, 2014), sobre a qual discorremos anteriormente.

Diferentemente dos gêneros do discurso, que possuem posições correlatas de produção e de recepção, a enunciação aforizante, explica Maingueneau (2015), estabelece uma cena de fala em que o aforizador (enunciador de uma aforização), fala a um auditório universal, não somente àquele referente ao gênero discursivo em que se insere.

\footnotetext{
Fundamentalmente monologal, a aforização tem como efeito centrar a enunciação no locutor. Considera-se que é o "próprio" indivíduo que se expressa. O aforizador, precisamente na medida em que não assume um papel prescrito pelo gênero de discurso, pode assumir a altura, expressar uma convicção, uma experiência, enunciar sua verdade, subtrair-se à negociação. (MAINGUENEAU, 2015, p. 134, grifo do autor)
}

O aforizador estabelece sua tese/convicção/verdade por meio da aforização produzida sem, no entanto, a necessidade de colocá-la ou argumentar sobre ela, como é possível ocorrer na enunciação textualizante. Nesse sentido, "bela, recatada e do lar" é colocada como uma máxima.

Maingueneau (2010) explana que outra característica da aforização é ser memorável. Enquanto a enunciação textualizante não é facilmente apropriada pela memória, a enunciação aforizante resulta, ainda que de forma utópica, em uma fala sempre disponível. Mais recentemente, com o advento da Internet e, principalmente, das redes sociais, a retomada de certas aforizações passa a ocorrer repetidamente, em situações diversas (conversas, programas de televisão, blogs, redes sociais...), fenômeno denominado como panaforização, combinação dos termos aforização e pan- de pandemia (MAINGUENEAU, 2014). Pela forma como "ela [a panaforização] satura de repente o espaço midiático que a impõe como objeto de discurso, como aquilo de que não se pode deixar de falar." (MAINGUENEAU, 2012, p. 18, grifo do autor), podemos classificar "bela, recatada e 'do lar"” como um desses casos.

Vejamos como essa (pan)aforização repercute na imprensa internacional logo após sua publicação pela Revista Veja. Não nos interessa, no entanto, analisar em detalhes os textos apresentados, tampouco discutir se os termos utilizados para "bela, recatada e do lar” em outras línguas são os mais apropriados ou não.

\author{
The hilarious feminist backlash to Brazil's impeachment fallout \\ Apr20,2016@12:31 PM \\ [...] \\ The latest issue of Veja magazine, Brazil's right-leaning mainstream media outlet, features a \\ profile spread on the wife of Brazil's current vice-president, Michel Temer, the man now \\ positioned to take over the country if Rousseff is formally ousted by a Senate trial in the \\ coming weeks. His wife is now viewed by many conservatives as the rising First Lady. \\ $[\ldots]$ \\ The headline reads: Marcela Temer: Bela, recatada, e "do lar" \\ Translation: Marcela Temer: Beautiful, maidenlike, and "a housewife"
}


The response? A whole lot of outrage. And a viral social media trend. "This article in Veja shows how our society is still extremely macho," says Carol Schmitz, a designer in Florianopolis, Brazil. She reads the headline as saying, "A model woman is maidenlike, demure, dresses in an appropriate way, and stays in the home. The underlying idea is that a good woman must stay quiet and simply accompany a man."

Fonte: <www.forbes.com/sites/shannonsims/2016/04/20/the-hilarious-feminist-backlash-tobrazils-impeachment-fallout/\#7abf940f59fa>. Acesso em: 30 jan. 2017.

A revista norte-americana de negócios e economia Forbes, que traduz "bela, recatada e do lar" por "beautiful, maidenlike, and a housewife", comenta o texto de Veja, destacando não apenas a reação negativa da população, mas também seu impacto nas redes sociais e como a matéria da revista reflete os valores machistas da sociedade brasileira.

O jornal El Comercio, o mais antigo jornal peruano, retoma a aforização traduzindo-a para o espanhol como "bella, recatada y del hogar". Novamente, há menção à repercussão nas redes sociais e à reação de mulheres indignadas com a publicação.

\section{El reportaje sobre la esposa de Temer que molestó a brasileñas}

Miles de mujeres manifestaron su desagrado sobre los términos en los que se definió a la esposa del vicepresidente de Brasil

21 de abril del 2016, 16:23

[...]

El polémico reportaje, publicado por la revista Veja, describe a Marcela Temer como una mujer "bella, recatada y del hogar", una serie de adjetivos que indignó a incontables mujeres en el país.

Las redes sociales se inundaron de fotografias en nada recatadas u hogareñas de mujeres a las que les desagradó que se defina en esos términos a la esposa de Michel Temer, quien podría relevar a Rousseff si prospera el juicio político con fines destituyentes que ahora tramita en el Senado.

Fonte: <http://elcomercio.pe/mundo/latinoamerica/reportaje-sobre-esposa-temer-quemolesto-brasilenas-noticia-1895943>. Acesso em: 10 jan. 2017.

O italiano La Repubblica destaca a polêmica gerada pelo texto de Veja e apresenta o termo "bella, timida e casalinga".

\footnotetext{
Marcela è una "bella casalinga": l'articolo del magazine Veja scatena la polemica

21 aprile 2016

$[\ldots]$

'Bella, timida e casalinga'. Marcela Tedeschi, quasi First Lady in quanto moglie di Michel Temer, il vicepresidente che sostituirà Dilma Rousseff, è stata descritta così da 'Veja', uno dei più importanti magazine brasiliani. Marcela, laureata in legge, 32enne, ha 43 anni meno di suo marito. Nell'articolo che parla di lei, si legge: ' $E$ ' una moglie che si comporta sempre bene, è discreta, parla poco, indossa sempre gonne sotto il ginocchio", e non ruba 387oloca scena al marito mostrandosi sempre docile e in secondo piano.

Fonte:

<www.repubblica.it/esteri/2016/04/21/foto/brasile_first_lady_marcela_tedeschi_twitter_polemi ca_-138102216/1/\#1>. Acesso em: 30 jan. 2017.
} 
Na França, o jornal Le Monde, à semelhança do italiano La Repubblica, se limita a reproduzir e comentar trechos do texto original de Veja. Publicada algumas semanas após a abertura no Senado do processo de impeachment de Dilma Rousseff e de seu afastamento temporário da presidência, a matéria já se refere a Marcela Temer como primeira-dama e traduz "bela, recatada e do lar" como "belle, réservée et au foyer".

\begin{abstract}
Au Brésil: Marcela, la femme du président Michel Temer, fait le buzz
Un portrait publié par la revue "Veja » a provoqué un déchaînement de la blogosphère contre la première dame.

27.05.2016 à $10 \mathrm{~h} 23$

$[\ldots]$

Le déchaînement de la blogosphère a commencé après la publication d'un portrait pour le moins déroutant, publié par la revue Veja, cataloguée politiquement à droite. Titré «Belle, réservée et au foyer ", on y découvre la vie mouvementée de la jeune mère de 33 ans, diplômée de droit, mais qui n'a sur son CV qu'un bref emploi de réceptionniste et deux participations à un concours de Miss dans l'Etat de Sao Paulo : amener son fils de 7 ans, « Michelzinho » à l'école, s'occuper de sa maison, « et d'elle aussi », précise Veja mentionnant deux visites chez le dermatologue. A l'occasion, dîner dans de grands restaurants avec son mari de 75 ans, qu'elle aime éperdument (le prénom de son époux est tatoué sur sa nuque).

Fonte: <www.lemonde.fr/international/article/2016/05/27/au-bresil-marcela-la-femme-dupresident-michel-temer-fait-le-buzz_4927491_3210.html\#8qkUWgusAC2F6hiR.99>.

Acesso em: 30 jan. 2017.
\end{abstract}

Percebemos, por meio dos exemplos anteriores, como um caso de panaforização pode se tornar um objeto de discurso e atravessar as fronteiras de própria língua em que foi originalmente enunciado. Ainda que publicado em diferentes idiomas, "bela, recatada e do lar" pôde suscitar a discussão a respeito do papel da mulher na sociedade.

Um dos fenômenos constitutivos da panaforização é seu relativo período curto de circulação e, eventualmente, sua substituição por outras (pan)aforizações. Ainda que não haja um limite transparente delimitando esse tempo de funcionamento, é possível notar que a panaforização continua funcionando de maneira autônoma e circulando em diferentes gêneros.

\title{
3 BELA, METAFORIZADA E DO HUMOR
}

Uma das formas de manifestação contra o que foi publicado por Veja se deu por meio de gêneros do discurso humorístico, especialmente pela postagem e compartilhamento de memes ${ }^{4}$ nas redes sociais. De modo geral, protestou-se por meio do humor contra a ideia de a mulher estar destinada somente a atividades domésticas, sendo alguém socialmente menos importante que o homem ou estando à sombra dele.

O meme apresentado pela Figura 1 exemplifica isso, associando a imagem da mulher à ideia de força e rompendo com a noção de "sexo frágil". O fato de a mulher empunhar uma arma de grosso calibre resgata a memória de alguém em combate,

\footnotetext{
${ }^{4}$. Imagem, informação ou ideia que se espalha rapidamente pela internet. Normalmente, é uma crítica humorística constituída por uma imagem (caricatura, desenho, foto etc.) e uma breve mensagem.
} 
tradicionalmente associada a homens (soldados). Notamos, no entanto, que os vasos de planta na imagem podem sugerir que a mulher está em casa. O humor nesse caso se faz presente na ideia de que ser "do lar" não faz da mulher alguém que não sabe como agir; pelo contrário, ela é alguém que usa de força bruta, se necessário, contrapondo o ethos discursivo construído no texto de Veja a respeito de Marcela Temer.

\section{Figura 1 - Meme a partir de "bela, recatada e 'do lar'"}

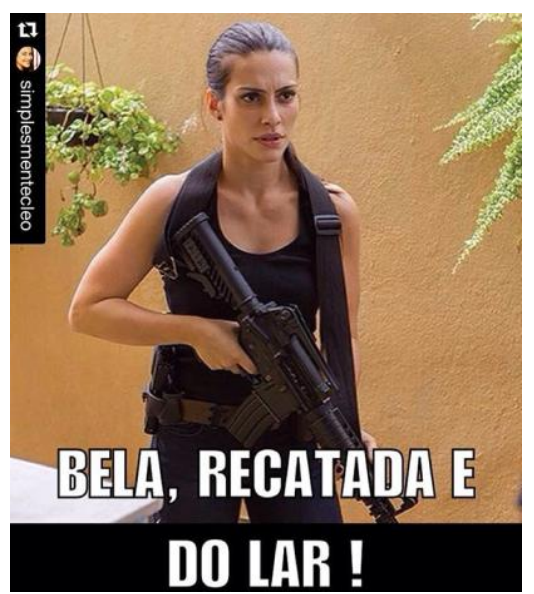

Fonte: 〈http://veja.abril.com.br/tecnologia/belarecatadaedolar-os-memes-sobre-a-reportagem-de-veja/>. Acesso em: 10 fev. 2017

Outros memes parodiaram a aforização original na intenção de romper com alguns estereótipos associados às mulheres. $\mathrm{O}$ meme da Figura 2, por exemplo, retoma a aforização "bela, recatada e do lar" e desloca dois de seus termos:

Figura 2 - Meme a partir de "bela, recatada e 'do lar'"

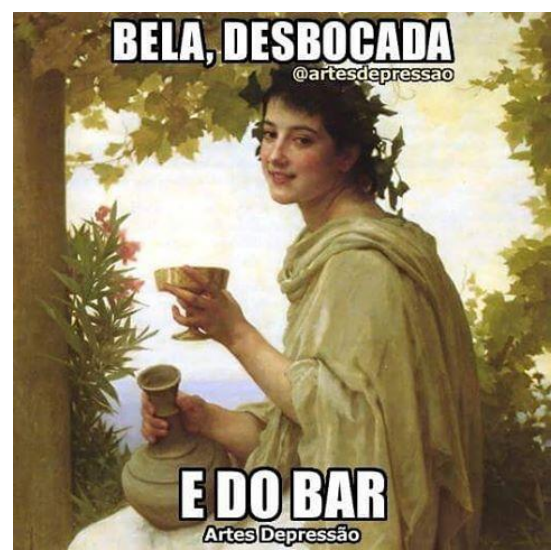

Fonte: <http://veja.abril.com.br/tecnologia/belarecatadaedolar-os-memes-sobre-a-reportagem-de-veja/>. Acesso em: 10 fev. 2017.

- "recatada" é substituído por "desbocada", isto é, aquela que diz grosserias e/ou obscenidades; que fala o que pensa; que não tem "papas na língua", em oposição ao "educadíssima" publicado por Veja a respeito de Marcela Temer; 
- "do lar" é substituído por "do bar". O efeito de sentido nesse caso é o de que a mulher não fica em casa esperando o marido, mas tem vida noturna, "sai na balada" e também bebe.

O termo bela não é, no entanto, alterado (nem nesse, nem em outros memes semelhantes), sugerindo que as mulheres não abrem mão da beleza como um aspecto essencial a respeito de si mesmas.

Por último, apresentamos mais um meme (Figura 3) que parodia a aforização publicada por Veja, fazendo, no entanto, uma crítica dentro do campo discursivo político.

Figura 3 - Meme a partir de "bela, recatada e 'do lar"”

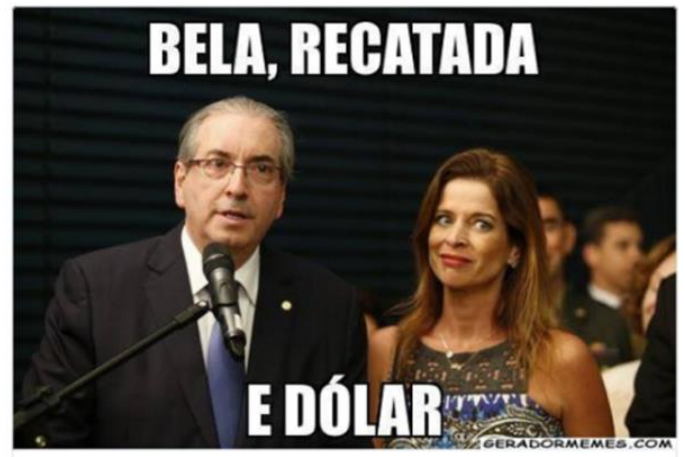

Fonte: <http://veja.abril.com.br/tecnologia/belarecatadaedolar-os-memes-sobre-a-reportagem-de-veja/>. Acesso em: 10 fev. 2017.

Os dois personagens da foto, Cláudia Cruz e seu marido, Eduardo Cunha, então presidente da Câmara dos Deputados, foram investigados pela Operação Lava-Jato por movimentações financeiras no Brasil e no exterior sob suspeita de lavagem de dinheiro. O autor do meme, ao se referir a Cláudia Cruz, manteve o "bela e recatada", à semelhança do que fora dito sobre Marcela Temer, mas fez um trocadilho com "do lar" que, na composição em uma só palavra e com a mudança da sílaba tônica de "lar" para "do", passou a "dólar". O efeito de sentido nesse caso é o de que Cláudia Cruz não ficaria em casa, mas que sairia para gastar muito dinheiro, em alusão às compras que realizava no exterior que, em 2016, compunham a denúncia de corrupção enviada ao Supremo Tribunal Federal.

Ao observar os desdobramentos e ocorrências de uma aforização ao longo de uma década, Baronas (2013) notou que uma mesma pequena frase foi enunciada em contextos distintos e por enunciadores distintos, sob diversos posicionamentos ideológicos, e concluiu que, a partir de (in)determinado momento, e por causa de sua intensa circulação, pode acontecer de uma (pan)aforização tornar-se uma metaforização, isto é, uma

\footnotetext{
pequena frase que assume o caráter de uma metáfora com intensa circulação, ou seja, uma frase que se presta por conta da sua constituição linguístico-discursiva (pregnância linguística e de sentidos) a estabelecer uma analogia de sentidos entre diferentes acontecimentos discursivos. (BARONAS, 2013, p. 241-242)
} 
Segundo o autor, a metaforização (proveniente da combinação de metáfora e aforização) constitui-se como um enunciado pronto para significar diferentes acontecimentos discursivos. De fato, é possível percebermos que a metaforização vai além do estatuto pragmático da panaforização: ela não é apenas fruto de uma intensa circulação discursiva, mas passa a ser uma metáfora disponível dentro de determinado universo discursivo (MAINGUENEAU, 1997) e sedimentada no imaginário coletivo. A partir dessas observações, Baronas (2013) revê o esquema proposto por Maingueneau (2010), como demonstrado pelo Quadro 2.

\section{Quadro 2 - Esquema das ordens enunciativas proposto por Maingueneau (2010) e revisto por Baronas (2013)}

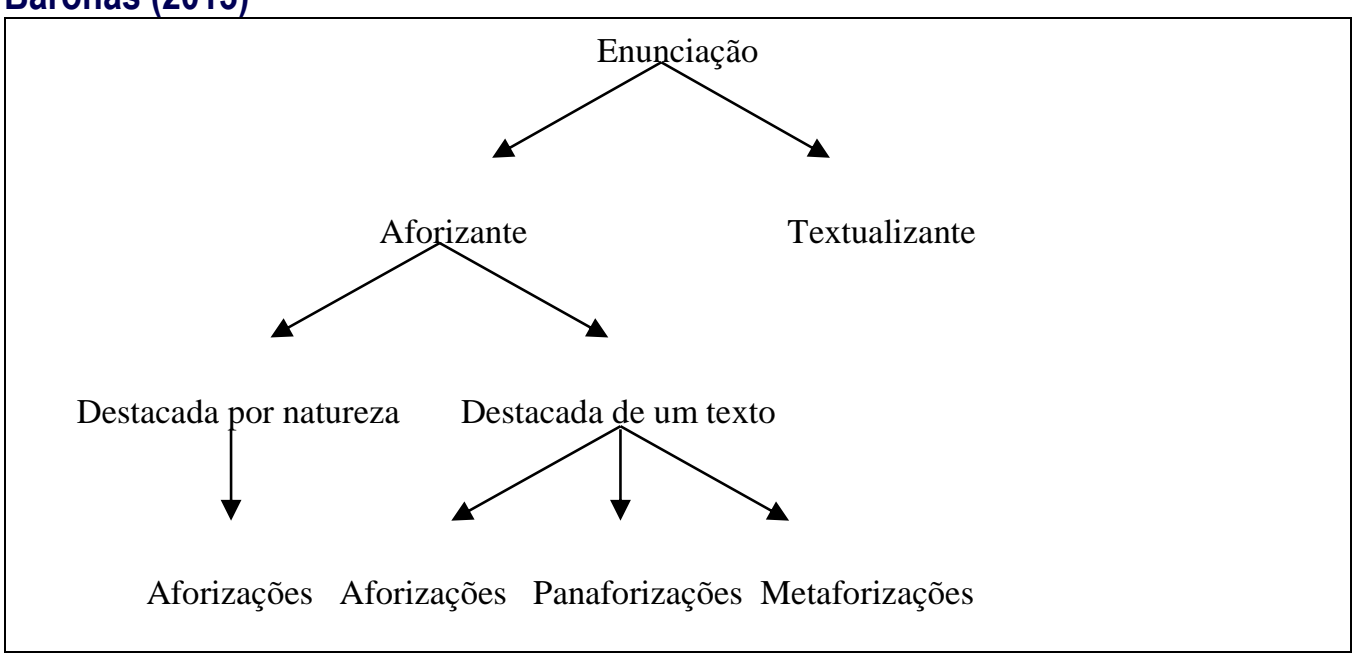

Fonte: Baronas, 2013, p. 242.

Nos textos a seguir, "bela, recatada e do lar" é retomado não mais como o "texto de Veja" ou "características de Marcela Temer", mas como uma metáfora que circula de forma independente, adquirindo, por vezes, novos sentidos.

\footnotetext{
Kate Middleton encarna velejadora em treino profissional

Da Redação

20 maio 2016, 16h41

Duquesa de Cambridge troca salto alto e vestido por uniforme esportivo

[...]

Kate Middleton tirou o figurino de bela, recatada e do lar para desfilar o uniforme esportivo de velejadora de um time britânico, do qual ela é considerada uma espécie de madrinha. O grupo, patrocinado por uma marca de carro, realizou nesta sexta-feira, em Portsmouth, na Inglaterra, um evento beneficente, que tem como plano auxiliar e incentivar 3.000 adolescentes a praticarem o esporte.

<http://veja.abril.com.br/entretenimento/kate-middleton-encarna-velejadora-em-treinoprofissional/>. Acesso em: 30 jan. 2017.
}

Nesse primeiro exemplo, "bela, recatada e do lar" é uma metáfora de um modelo de vestimenta ("o figurino") que inclui salto alto e vestido, ao contrário daquilo que é posto para Marcela Temer, a quem também se atribui um tipo de comportamento, um 
conjunto de regras sociais a serem seguidas: não apenas vestir-se de forma discreta, mas aparecer pouco em público, cumprir seus afazeres rotineiros de mãe e esposa, dedicar-se ao lar.

Outro exemplo:

\author{
Até quando julgaremos as vítimas de estupro? \\ Cláudia Colluci \\ 31 maio 2016, $01 \mathrm{~h} 41$ \\ $[\ldots]$ \\ Como veem, só mudam os atores e os cenários. A impiedosa e moralista plateia permanece \\ a mesma, sempre desmerecendo, julgando e condenando as vítimas de estupro que não se \\ enquadram no padrão "bela, recatada e do lar". \\ Fonte: <www1.folha.uol.com.br/colunas/claudiacollucci/2016/05/1776509-ate-quando- \\ julgaremos-as-vitimas-de-estupro.shtml>. Acesso em: 30 jan. 2017.
}

Temos aqui a associação de "bela, recatada e do lar" como metáfora para protocolo social, como o padrão a ser seguido pelas mulheres para que, em casos de estupro, elas não sejam "moralmente desmerecidas, julgadas e condenadas". Subjaz a concepção machista de que socialmente as mulheres que estão fora do modelo social são pessoas sujeitas ao estupro.

Consideremos a próxima ocorrência:

\begin{abstract}
A 'Riqueza' na vida do ex-governador do Rio Sérgio Cabral
Gilberto Amendola, enviado especial

26 novembro 2016, $21 \mathrm{~h} 46$

[...]

Adriana não foi uma primeira dama vocacionada. No começo, claro, envolveu-se em projetos sociais, organizou jantares beneficentes e cumpriu o papel de "bela, recatada e do lar". Mas, tirando um ou outro momento em que ciceroneou estrelas internacionais do calibre de Madonna e Carla Bruni, Adriana não demonstrou paciência para cumprir o protocolo.

$[\ldots]$

Fonte: <http://politica.estadao.com.br/noticias/geral,a-riqueza-na-vida-do-ex-governadordo-rio-sergio-cabral,10000090900/>. Acesso em: 30 jan. 2017.
\end{abstract}

De forma prática, o que exatamente viria a ser "cumprir o papel de bela, recatada e do lar"? Não há nesse trecho uma explicação clara do que isso significa, deixando a cargo do leitor o resgate da memória discursiva referente ao termo. À semelhança do exemplo anterior, há um leve deslocamento do sentido original: "bela, recatada e do lar" assume a forma de protocolo político, uma metáfora a respeito do papel a ser encenado pelas esposas de ocupantes de cargos públicos, recuperando a memória de que "lugar de mulher" não é exercendo atividades políticas, cabendo-lhe o papel de benfeitora social.

A seguir, um caso em que "bela, recatada e do lar" funciona como sinônimo de "dona de casa". 


\section{Jovem da periferia dribla desejo dos pais por sonho de entrar na Unicamp}

Estudante quer fazer artes cênicas, e não ser 'bela, recatada e do lar'. Segunda fase do processo seletivo começa neste domingo (15)

Por Fernando Evans

14 jan 2017, 06h00

Vencer barreiras é uma lição que se aprende cedo nas periferias das grandes cidades. E é com a experiência de quem ultrapassou muitas delas que a jovem Ana Gabriela Souza Macena, de 19 anos, encara a $2^{a}$ fase do Vestibular da Unicamp, que começa neste domingo (15).

Mais do que superar as dificuldades sociais, ela encara barreiras dentro da família nessa caminhada até o ensino superior. Por conta da religião, seus pais imaginavam outro destino para a filha. "Eles gostariam que eu me simplesmente me tornasse dona de casa. Bela, recatada e do lar, não!", avisou...

[...]

Fonte: <http://g1.globo.com/sp/campinas-regiao/noticia/2017/01/jovem-da-periferia-dribladesejo-dos-pais-por-sonho-de-entrar-na-unicamp.html/>. Acesso em: 30 jan. 2017.

Ainda que a noção inicial publicada por Veja não remetesse apenas ao conceito de mulher como "dona de casa", na notícia anterior esse conceito é usado como equivalente a "bela, recatada e do lar". Como a jovem refuta esse rótulo porque quer estudar, "bela, recatada e do lar" funciona como metáfora de mulher que não quer estudar para ser independente.

\section{De prazer anal a palavrão: 5 vezes em que Sandy largou de ser certinha}

Do UOL, em São Paulo

25 jan. 2017, 04h00

Se tem uma coisa que o sucesso conquistado na infância rendeu para Sandy, além de milhões, foi a obrigação de manter uma certa fama de santinha ao longo dos anos.

A cantora começou a carreira aos sete anos ao lado do irmão na dupla Sandy e Júnior, e, assim como outras estrelas infantis que cresceram sob os holofotes, precisou construir uma imagem de bela, recatada e do lar que se adequasse ao público que a idolatrava.

É bem verdade que Sandy nunca "despirocou" como algumas ex-celebridades infantis, tipo Lindsay Lohan e Britney Spears, mas a filha de Xororó, hoje com 33 anos, tem cada vez mais se permitido brincar com o estereótipo que carregou por toda a infância e adolescência.

$[\ldots]$

Fonte: <https://tvefamosos.uol.com.br/listas/de-prazer-anal-a-palavrao-na-tv-5-vezes-quesandy-largou-de-ser-certinha.htm/>. Acesso em: 30 jan. 2017.

Neste último exemplo, a metáfora de "bela, recatada e do lar", usada para designar a atitude de Sandy durante sua juventude, é construída por meio de possíveis antônimos para a noção que o termo traz, tais como "largar de ser certinha" e "despirocar" (endoidar, pirar), e por atitudes que, dentro do imaginário construído em torno da máxima, não são possíveis ou permitidas: falar sobre assuntos relativos à sexualidade ou dizer palavrões, como evidenciado pelo título.

Ainda que Baronas (2013) afirme que a metaforização é resultado de anos de constância enunciativa, não nos é possível afirmar neste momento quais os futuros desdobramentos de "bela, recatada e do lar". No entanto, como demonstrado pelos exemplos anteriores, já nos é possível perceber que, mesmo menos de um ano após a publicação de Veja, o termo já ganha os contornos de uma metáfora linguisticamente passível de ser acessada de formas diferentes. 
O perfil de Marcela Temer, publicado em 18 de abril de 2016, um dia após a votação do processo de impeachment na Câmara dos Deputados, já a anunciava como "quase primeira-dama", de forma que se pode atribuir para a Revista Veja uma posição favorável à destituição da presidente Dilma Rousseff do poder, o que, oficialmente, aconteceu em 31 de agosto de 2016.

Muito mais do que antecipar a deposição de uma mulher à frente do governo, ao colocá-la como futura primeira-dama, a enunciação "Marcela Temer: bela, recatada e 'do lar'”, construída por meio de uma aforização-eco e uma fórmula triádica que se revela no formato de máxima, já possibilita a discussão da presença de um posicionamento sexista de que à mulher não cabe o protagonismo, mas o papel de consorte.

As retomadas do título em textos jornalísticos publicados em outros países também insinuam o machismo existente no país, e as remissões e transformações dos textos humorísticos, panaforizados em memes, criticam as escolhas lexicais adotadas na construção do perfil. A censura à publicação normalmente mantém a proposição de que as mulheres são belas (exceto pela condenação desse qualificador por meio de imagens que possam fugir ao padrão de belo socialmente aceito), mas modificam as características recatada e do lar por meio de desbocada, do bar e outras similares, como pode ser visto no meme da Figura 4.

\section{Figura 4 - Meme a partir de "bela, recatada e 'do lar'”}

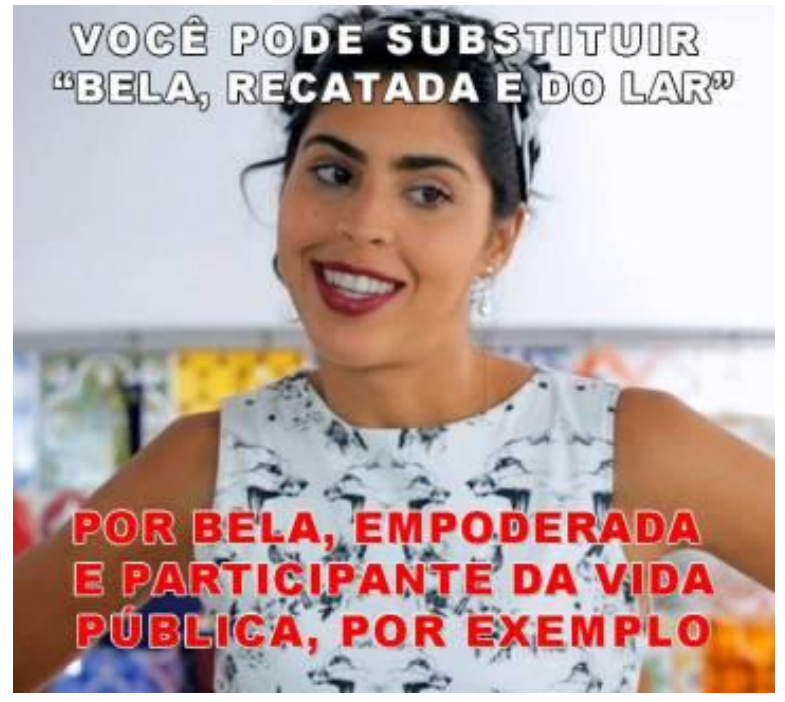

Fonte: <http://www.folhadoslagos.com/politica/politica/movimento-bela-recatada-e-do-lar-ganha-ainternet?fb_comment_id=1145928605459085_1146388502079762\#f26ddcf294f6eec/>. Acesso em: 10 fev. 2017.

A máxima construída por meio do título um ano após sua publicação ainda é recuperada em outras enunciações. Sua circulação ratifica uma posição secundária e decorativa para a mulher, confirmada por meio das seguintes metaforizações (Quadro 3): 
Quadro 3 - Metáforas para "bela, recatada e 'do lar'"

\begin{tabular}{|l|l|}
\hline $\begin{array}{l}\text { "tirou o figurino de bela, recatada e do lar para desfilar o } \\
\text { uniforme esportivo de velejadora" }\end{array}$ & $\begin{array}{l}\text { figurino discreto (salto e vestido) } \\
\text { f vestimenta esportiva }\end{array}$ \\
\hline $\begin{array}{l}\text { "as vítimas de estupro que não se enquadram no padrão "bela, } \\
\text { recatada e 'do lar"”. }\end{array}$ & protocolo social \\
\hline $\begin{array}{l}\text { "envolveu-se em projetos sociais, organizou jantares } \\
\text { beneficentes e cumpriu o papel de "bela, recatada e "do lar"” }\end{array}$ & protocolo político \\
\hline $\begin{array}{l}\text { "Estudante quer fazer artes cênicas, e não ser "bela, recatada e } \\
\text { do lar". }\end{array}$ & dona de casa \\
\hline $\begin{array}{l}\text { "assim como outras estrelas infantis que cresceram sob os } \\
\text { holofotes, precisou construir uma imagem de bela, recatada e do } \\
\text { lar que se adequasse ao público que a idolatrava" }\end{array}$ & atitude "certinha" \\
\hline
\end{tabular}

Relacionando o sentido primário da frase aos sentidos metaforizados, para a mulher mantém-se o papel de vestir-se de forma a parecer séria e elegante, o que não é possível pela utilização de roupas esportivas, nem que fujam ao padrão discreto. Assim, o que distinguir-se deste padrão não é "belo".

Cabe ainda à mulher manter atitudes circunspectas, de forma que fugir ao que não seja "certinho" ou que não atenda aos protocolos sociais pode ser passível de sofrimento como a violência moral, sexual ou a perda do carinho do outro. A mulher precisa ser "recatada".

Além de bela e recatada, à mulher cumpre o dever de ser "do lar", isto é, de desempenhar os protocolos familiares e políticos, quer por meio do atendimento ao marido e à família, quer por suas "obrigações" sociais impostas pelos cargos ocupados pelo marido. Recupera-se também o dito popular segundo o qual atrás de um grande homem há sempre uma grande mulher, isto é, as "primeiras-damas" do país ou do lar a quem cabe organizar o lar e/ou ações sociais.

Infelizmente, percebe-se que as críticas populares sociais ao "bela, recatada e do lar", panaforizadas em memes contra a ideia de que a mulher deve ocupar unicamente uma posição secundária de acompanhante do marido e administradora do lar, não impedem que as metaforizações se mantenham sexistas e estejam ligadas à primeira enunciação por meio dos não ditos. Esses não ditos estão ancorados nos estereótipos sociais e nos padrões socialmente aceitos. Assim, na enunciação "(vítimas de estupro) não se enquadram no padrão "bela, recatada e do lar", aponta-se que no Brasil há um padrão socialmente aceito de mulher "virtuosa" em oposição àquelas que são "devassas".

Também se espera que mulheres de políticos (ou as esposas em geral) atendam ao protocolo de serem as acompanhantes dos maridos em eventos nos quais devem saber se portar de forma discreta, como em "cumpriu o papel de "bela, recatada e do lar". Mas, tirando um ou outro momento [...] não demonstrou paciência para cumprir o protocolo". Ou de que o papel desejável para as mulheres é apenas o de dona de casa: "Eles gostariam que eu me simplesmente me tornasse dona de casa. Bela, recatada e do lar, não!, avisou...”. 
Os processos de aforização, panaforização e metaforização estudados possibilitam afirmar que na mídia brasileira, incluindo as redes sociais, há um descompasso entre o que é dito, o que se espera ser dito e os não ditos em relação ao papel da mulher. Persiste uma ideologia machista em que o protagonismo feminino deve se manter apenas no lar.

\section{REFERÊNCIAS}

BARONAS, R. L. Da panaforização à metaforização: o caso de uma pequena frase sem eira nem beira textual. Revista da ABRALIN, v.12, n.2, p. 219-248, jul./dez. 2013.

BIBLIA Online. Disponível em <http://bibliaportugues.com/kja/proverbs/31.htm>. Acesso em: 15 jan. 2017.

DIAS, A. R. F. O discurso da violência - as marcas da oralidade no jornalismo popular. São Paulo: EDUC/ Cortez, 1996.

LINHARES, J. Marcela Temer: bela, recatada e "do lar". Veja.com. Disponível em: <http://veja.abril.com.br/brasil/marcela-temer-bela-recatada-e-do-lar/>. Acesso em: 26 ago. 2016.

MAINGUENEAU, D. Discurso e análise do discurso. São Paulo: Parábola Editorial, 2015.

Frases sem texto. São Paulo: Parábola Editorial, 2014.

Análise de textos de comunicação. 6. ed. ampliada. São Paulo: Cortez, 2013.

Aforizações políticas, mídias e circulação de enunciados. Linguasagem - Revista Eletrônica de Popularização Científica em Ciências da Linguagem, São Carlos, n. 20, p.1-18, out./dez. 2012.

Doze conceitos em análise do discurso. São Paulo: Parábola Editorial, 2010.

. Cenas da enunciação. São Paulo: Parábola Editorial, 2008a.

A propósito do ethos. In: MOTTA, A. R.; SALGADO, L. (Org.). Ethos discursivo. São Paulo: Contexto, 2008b. p.11-29.

. Novas tendências em análise do discurso. 3. ed. Campinas: Pontes, 1997.

ANEXO

\section{Marcela Temer: bela, recatada e "do lar"}

A quase primeira-dama, 43 anos mais jovem que o marido, aparece pouco, gosta de vestidos na altura dos joelhos e sonha em ter mais um filho com o vice

Por Juliana Linhares

18 abr. 2016, 19 h14

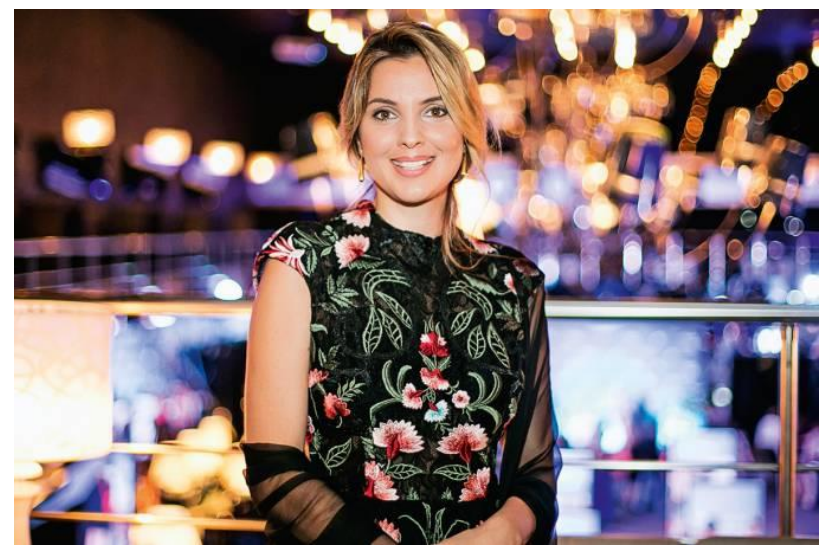

Marcela, mulher do vice, Michel Temer: jantares românticos e apelidos carinhosos

(Bruno Poletti/Folhapress) 
Marcela Temer é uma mulher de sorte. Michel Temer, seu marido há treze anos, continua a lhe dar provas de que a paixão não arrefeceu com o tempo nem com a convulsão política que vive o país - e em cujo epicentro ele mesmo se encontra. Há cerca de oito meses, por exemplo, o vice-presidente, de 75 anos, levou Marcela, de 32, para jantar na sala especial do sofisticado, caro e badalado restaurante Antiquarius, em São Paulo. Blindada nas paredes, no teto e no chão para ser à prova de som e garantir os segredos dos muitos políticos que costumam reunir-se no local, a sala tem capacidade para acomodar trinta pessoas, mas foi esvaziada para receber apenas "Mar" e "Mi", como são chamados em família. Lá, protegido por quatro seguranças (um na cozinha, um no toalete, um na entrada da sala e outro no salão principal do restaurante), o casal desfrutou algumas horas de jantar romântico sob um céu estrelado, graças ao teto retrátil do ambiente. Marcela se casou com Temer quando tinha 20 anos. O vice, então com 62, estava no quinto mandato como deputado federal e foi seu primeiro namorado.

Michelzinho, de 7 anos, cabelo tigelinha e uma bela janela no lugar que abrigará seus incisivos centrais, é o único filho do casal (Temer tem outros quatro de relacionamentos anteriores). No fim do ano passado, Marcela pensou que esperava o segundo filho, mas foi um alarme falso. "No final, eles acharam que não teria sido mesmo um bom momento para ela engravidar, dada a confusão no país", conta tia Nina, irmã da mãe de Marcela. Ela se refez do sobressalto, mas não se resignou - ainda quer ter uma menininha. No Carnaval, Marcela planejou uns dias de sol e praia só com o marido e o filho e foi para a Riviera de São Lourenço, no Litoral Norte de São Paulo. Temer iria depois, mas, nos dias seguintes, o plano foi a pique: o vice ligou, dizendo que estava receoso de expor a família, devido aos ânimos acirrados no país. Pegou Marcela, Michelzinho, e todo mundo voltou para casa.

Bacharel em direito sem nunca ter exercido a profissão, Marcela comporta em seu curriculum vitae um curto período de trabalho como recepcionista e dois concursos de miss no interior de São Paulo (representando Campinas e Paulínia, esta sua cidade natal). Em ambos, ficou em segundo lugar. Marcela é uma vice-primeira-dama do lar. Seus dias consistem em levar e trazer Michelzinho da escola, cuidar da casa, em São Paulo, e um pouco dela mesma também (nas últimas três semanas, foi duas vezes à dermatologista tratar da pele).

Por algum tempo, frequentou o salão de beleza do cabeleireiro Marco Antonio de Biaggi, famoso pela clientela estrelada. Pedia luzes bem fininhas e era "educadíssima", lembra o cabeleireiro. "Assim como faz a Athina Onassis quando vem ao meu salão, ela deixava os seguranças do lado de fora", informa Biaggi. Na opinião do cabeleireiro, Marcela "tem tudo para se tornar a nossa Grace Kelly". Para isso, falta só "deixar o cabelo preso". Em todos esses anos de atuação política do marido, ela apareceu em público pouquíssimas vezes. "Marcela sempre chamou atenção pela beleza, mas sempre foi recatada", diz sua irmã mais nova, Fernanda Tedeschi. "Ela gosta de vestidos até os joelhos e cores claras", conta a estilista Martha Medeiros.

Marcela é o braço digital do vice. Está constantemente de olho nas redes sociais e mantém o marido informado sobre a temperatura ambiente. Um fica longe do outro a maior parte da semana, uma vez que Temer mora de segunda a quinta-feira no Palácio do Jaburu, em Brasília, e Marcela permanece em São Paulo, quase sempre na companhia da mãe. Sacudida, loiríssima e de olhos azuis, Norma Tedeschi acompanhou a filha adolescente em seu primeiro encontro com Temer. Amigos do vice contam que, ao fim de um dia extenuante de trabalho, é comum vê-lo tomar um vinho, fumar um charuto e "mergulhar num outro mundo" - o que ocorre, por exemplo, quando telefona para Marcela ou assiste a vídeos de Michelzinho, que ela manda pelo celular. Três anos atrás, Temer lançou o livro de poemas intitulado Anônima Intimidade. Um deles, na página 135, diz: "De vermelho / Flamejante / Labaredas de fogo / Olhos brilhantes / Que sorriem / Com lábios rubros / Incêndios / Tomam conta de mim / Minha mente / Minha alma / Tudo meu / Em brasas / Meu corpo / Incendiado / Consumido / Dissolvido / Finalmente / Restam cinzas / Que espalho na cama / Para dormir".

Michel Temer é um homem de sorte.

Recebido em: 01/03/17. Aprovado em: 16/09/17. 
Title: Beautiful, panaphorized and a housewife: reflections upon a case of aphorization Authors: Rafael Prearo-Lima; Patrícia Silvestre Leite Di Iório

Abstract: In this work, we analyze the process of aphorization regarding the title of the profile "Marcela Temer: bela, recatada e 'do lar"” [Marcela Temer: beautiful, maidenlike, and "a housewife"], published by Revista Veja Online, in April 18 ${ }^{\text {th }}$, 2016. The period, marked by political and social polarizations and by President Dilma Rousseff's impeachment process, has been considered fruitful to the (con/di)vergence of the memories provided by the triad "beautiful, maidenlike, and a housewife" and thereunto, to the discussion of the Brazilian sexism which resonates, among others, in the news, in criticisms and in humoristic texts. We intend to verify how the title of the profile is built by the process of remission as an echo-aphorization, how it is panaphorized and metaphorized. In this analysis, we will use the concepts of the French discourse analysis, mainly the studies by Maingueneau (2010, 2012, 2014) and Baronas (2013).

Keywords: Media. Aphorizing Enunciation. Panaphorization. Metaphorization.

Título: Bella, panaforizada y del hogar: reflexiones sobre un caso de aforización

Autores: Rafael Prearo-Lima; Patrícia Silvestre Leite Di Iório

Resumen: En este trabajo analizamos el proceso de aforización del título del perfil "Marcela Temer: bela, recatada e 'do lar'”' [Marcela Temer: bella, recatada y 'del hogar'], publicado por la Revista Veja Online en 18 de abril de 2016. El periodo, marcado por polarizaciones políticas y sociales y por el proceso de impeachment de la Presidenta Dilma Rousseff, se ha mostrado productivo para la (con/di)vergencia de las memorias instituidas por la tríada "bella, recatada y del hogar", y en consecuencia, para la discusión del sexismo brasileño que ha repercutido, entre otros, en noticias, críticas y textos humorísticos. Hemos buscado verificar como el título del perfil es construido por el proceso de remisión, se constituyendo en una aforización-eco, cómo él es panaforizado y metaforizado. Para el análisis, nos utilizamos de conceptos del Análisis del Discurso, principalmente los propuestos por Maingueneau (2010, 2012 y 2014) y Baronas (2013).

Palabras-clave: Media. Enunciación aforizante. Panaforización. Metaforización.

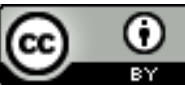

Este texto está licenciado com uma Licença Creative Commons Atribuição 4.0 Internacional. 